\title{
Lamarck y las indexadas
}

\section{Ignacio Paricio}

"A medida que los individuos ..... cambian de hábito ....reciben
influencias que cambian poco a poco las proporciones de sus
partes ... sus facultades y hasta su misma organización" partes ... sus facultades y hasta su misr

E I profesor Tremendo Curriculum se despertó apoyado en - su mesa de trabajo. Se había quedado dormido sobre un papel en blanco donde debía plasmar sus nuevas ideas, las líneas de investigación para el año que empezaba. Tenía un dolor de cabeza notable. Desde hacía un tiempo notaba un extraño bulto en nada. Increíblemente el famoso investigador estaba seco.

Inquieto, se volvió hacia el montoncillo de artículos a publicar. La especialista Indexación Garantías se los había dejado listos para enviar. ¡Qué chica mas maja! Calculó rápidamente los puntos que enviar. ¡Qué chica mas maja! Calculo rápidamente los puntos que dos y ahora debidos. Sonrió ante el numero de créditos que se le iban a conceder. Entró en el software en el que se contabilizan sus "puntos" como investigador y sonrió. Una oleada de placer recorrió su mente reconociendo la facilidad con la que se movía en esa laberíntica trama inquisitorial que tantas dificultades le había planlaberíntica trama inquisitorial que tantas dificultades le había planni la única manera de evaluar su trabajo. El bulto en el temporal se activó y pareció crecer mientras calculaba.

Se volvió hacia el papel en blanco para retomar la orientación de los proyectos de futuro, para intentar de nuevo activar su reconocida creatividad. Nada, estaba vacío. El dolor de cabeza se cambió al lado derecho. Curiosamente tenía la sensación de que ese temporal se deprimía. iiDios mío!! ¿Es que no se le iba a ocurrir nada que impulsase la línea de investigación que le había hecho famoso unos años atrás?

Sus colaboradores le esperaban para la reunión del grupo de investigación. Todos ellos necesitaban esas ideas que debían alimentar sus curriculums. Por cierto, que Trilero Investigador estaba pidiendo otro sexenio. Se le estaba acercando peligrosamente en pidiendo otro sexenio. Se le estaba acercando peligrosamente en
los puntos. No había problema, tenía recursos. Dulcemente, suavemente se activó el hemisferio izquierdo. Ya no dolía, era agradable recordar que solo tenía que llamar a su profesora asociada dable recordar que solo tenía que llamar a su pro
Creatividad Gestora para solucionar el problema.

No eran malos sus chicos. Quizás un poco demasiado ambiciosos y focalizados en la evaluación cuantitativa. Sobre todo esa chica del este, Suma Puntos. No tenía pudor. Pero bueno, mientras siguiese colocándole en todos sus trabajos como coautor... Aunque a veces eran insignificantes ... todo suma, señorita Suma.

\section{La implantación extensiva y aditiva como método histórico de intervención en arquitectura}

\section{Arcadi Pla i Masmiquel}

\begin{abstract}
a arquitectura debe tener potencialidades híbridas; en el preL sente momento histórico, lleno de revisiones y recapacitaciones, se hace más necesaria que nunca la capacidad de evolución, adición y crecimiento de los edificios, tan natural y propia del pasado. En contra de arquitecturas cerradas en sí mismas, que no aceptan la evolución sociologica de costumbres y necesidades de los usuarios ni la adaptación a las nuevas necesidades y costes eneracumulación de sistemas y tipos, puede ser mas adecuada.
\end{abstract}

En este sentido, afrontamos la restauración de la rectoría de la Capilla románica de Sant Martí de Solamal en el Valle de Bianya, Capilla románica de Sant Martí de Solamal en el Valle de Bianya, en la comarca gerundense de La Garrotxa, más como una suma unitaria y cerrada en su uso.

En las edificaciones rurales y masías tradicionales era habitual la construcción de cuerpos añadidos para ampliar las instalaciones, cada uno de ellos ejecutado con los medios y tecnologías constructivas que correspondian a cada época; en ese sentido es importante subrayar la idea que de que solo se interviene en lo construido a partir de lo contemporáneo.

La ermita de Sant Martí de Solamal se entiende a través de las diversas transformaciones que ha recibido, desde el siglo X, siendo una capilla de una sola nave hasta el siglo XII, su ampliación con dos naves laterales en el XVI y, finalmente, con la adicion de la sacristía (XVIII) y la rectoría (XIX). De esta manera no es una edificación, sino un conjunto que se enriquece con los elementos de la explotación agraria como el pajar cubierto o las zonas de trabajo.

El proyecto, debido a esos valores acumulados por la historia del lugar, no se plantea como una reforma sino como un plan global de restitución de la historia del lugar y su adaptación a las nuevas necesidades de este momento. Para cada actuación se delimita la estrategia constructiva y compositiva, aportando un conjunto
Incompetente. Demasiadas historias en común. Por suerte se le había ocurido una solución brillante. La universidad acababa de aprobar el reconocimiento como investigación de las horas de gestión. Menos mal, eso cerraba el círculo virtuoso: tenemos que hacer mucha gestión para permanecer a flote en este mundo investigador, por lo tanto es lógico que se reconozca esa dedicación administrativa como méritos investigadores y capacidad creativa. $Y$ ese es el futuro de mi inefable Aceptado.

Dios mío, jaún tenía que hojear la tesis de esa chica vasca, Enkuaderna Kualkierkosa! Por cierto ... ¿a quién iba a poner en el tribunal de una cosa tan flojita? ¡Ah sí, claro, a aquella italiana tan mona..! Cómo se llamaba ... Mañana Pormí.

Sus ojos se volvieron hacia su lectura abandonada hace unos meses. Sí, aquello de Lamarck: la función crea el órgano. No recordaba muy bien por qué lo estaba leyendo, pero sintió que le había afectado. Apartó de su mente esos pensamientos negativos. Se encontraba bien. No sentía ninguna necesidad de ahondar en esas inquietudes.

¡Qué raro! Se estaba palpando la cabeza y, aunque ya no le dolía, su temporal derecho parecía hundido.

PD.- Después de redactar la fábula anterior, leo en el País (14/06/13) el artículo de Holm-Detlev Köhler a propósito de la entrega del último premio Príncipe de Asturias a la socióloga Saskia Sassen. "La tercera enseñanza de Saskia Sassen nos lleva a la guido ningún mas importantes de nuestrá expoca no ha consede nuestras agencias de evaluación, que anteponen siempre el mismo criterio: tres publicaciones JCR (Journal Citation Reports) mismo criterio: tres publicaciones JCR (Journal Citation Reports) en los últimos cinco años. Sassen no tiene ni una, sino que ha publicado libros e informes, fruto de proyectos de investigación de verdad y referencias fundamentales para académicos compromesion, etc., pero se ha resistido a la práctica de inflar su currículum cír articulos estandarizados sin interés ni lectores, más allá de circulos de amigos do citación mutua. Estamos entregando nuestra calidad científica a Thompson Reuters (la empresa gestora de los JCRs) igual que la calificación de nuestras economías a Fitch, Moody's y Standard \& Poor's. La estandarización de nuestra enseñanza universitaria y de nuestra producción científica nos llevará a universidades sin debates, investigaciones sin compromiso y un sistema académico sin pensamiento.

Ignacio Paricio es Doctor arquitecto y catedrático del Departamento de Composición de la E.T.S.A.Barcelona. futura quiebra de nuestro sistema académico-universitario. Una de

la obra. Por último, la clave es que el conocimiento ha de ser comunicable y muchas veces los arquitectos pragmáticos, por muy buenas obras que realicen, no son capaces de comunicar procesos, significados y usos.

Y aquí aparece otra cuestión clave: la transmisión de conocimiento a través de los nuevos medios, especialmente en Internet. Por una parte, estas redes de comunicación están cambiando los modos y ritmos de transmisión del saber pero, por otra, la gran variedad hace que unas tengan

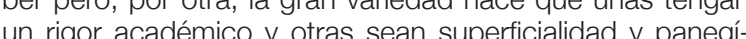
rico. ¿Cómo introducir en estos medios las pautas de los métodos de investigación y transmisión del saber, y cómo metodos de investigación y transmisión del saber, y cómo incorporar los valores de lo que se edita en estos medios en los criterios de valoración académicos? Visibilizando en qué medida han tenido capacidad de cambiar las coordenadas y recurriendo a expertos en estos nuevos formatos que
aporten criterios críticos equiparables a los que ya tienen las aporten criterios críticos equiparaciones convencionales.

\section{Por una teoría pragmática}

Este contexto reclama que las nuevas teorías partan de otras coordenadas: rechazo a la pretendida autonomía de la forma arquitectónica en relación a lo político y social; sintonía con todo tipo de medio de comunicación y con las posibilidades de las industrias locales; incorporación de as nuevos modos de trabajo colectivo y de cooperacion. Todo ello se desarrolla en el futuro libro Del diagrama a las experiencias, hacia una arquitectura de la acción. Mientras abstracto de los diagramas, ha de enraizarse en la vida y la experiencia, reencontrándose con la vertiente activista y experimental que tuvo en otros momentos.

Este proceso de transformación, altamente esperanzador, está caracterizado por este pragmatismo que huye de teorías previas e intenta aprender de la experiencia. La insistencia en la pragmática es un rasgo positivo y está relacionada cia en la pragmática es un rasgo positivo y está relacionada cado losis de realismo, intervenir en realidades concretas. De la lógica productivista e impositiva de la prefabricación y de los aprioris platónie impositiva de la prefabricación y de los aprioris platónicos de la crítica tipológica se ha pasado a la rehabilitación, a operaciones versátiles de menor tamaño y a una mayor capacidad de encaje en el contexto y de creación de vida vecinal. Véanse, como ejemplo, los libros que explican las intervenciones de la ONG Architecture for Humanity escritos por sus fundadores, Cameron Sinclair y Kate Stohr, marcados por este optimismo de la estrategia, la pragmática y la operatividad: esta arquitectura de cooperación se va aprenfuerte base teórica inicial lo que les lanzó a crear el colectivo y la actividad.

Es en este panorama de mutación que las propuestas auténticas relacionadas con el activismo social han podido avanzar: ONGs, grupos activistas, colectivos, experiencias de cooperación, etc. En cambio, la esfera académica tiene de cooperacion, etc. En cambio, la esfera academica tiene encerrada en su mundo de élite, de autosatisfacerse con encerrada en su mundo de elite, de autosatisfacerse con dicalidad de un proyecto crítico. Un riesgo que es posible dicalidad de un proyecto crítico. Un riesgo que es posible la construcción de interpretaciones y propuestas en relación a la sociedad y a la praxis; con la construcción de una nueva relación dialéctica entre la teoría y la práctica.

ARCHITECTURE FOR HUMANITY (Ed.) Design Like You Give a Damm (2).
Building Change from the Ground Up, Abrams, New York, 2012.

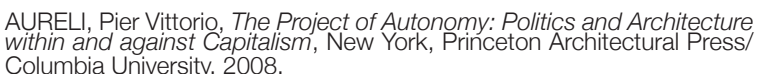
Columbia University, 2008

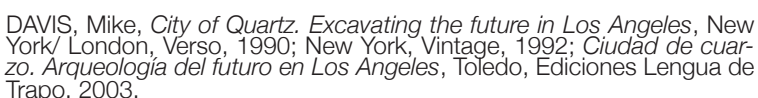

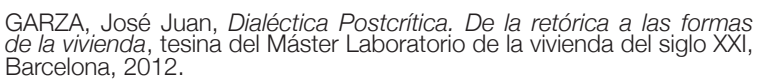

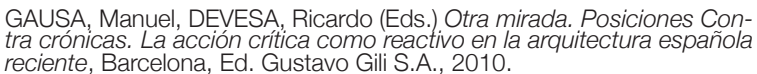
GUATTARI, Félix, Las tres ecologías, Valencia, Pre-Textos, 1990. HARRIES, Karsten, The Ethical Function of Architecture. Cambridge,
Mass., The MIT Press, 1997 . HAYDEN, Dolores, The Power of Place. Urban Landscapes as Public
History, Cambridge, Mass., The MIT Press, 1995 . MARTínEZ, Francisco José, Hacia una era post-mediática. Ontología,
politica y ecología en la obra de Félix Guattari, Mataró/Barcelona, Mon-
tesinos, 2008. MONTANER, Josep Maria, Arquitectura y critica, Ed. Gustavo Gili S.A.,
Barcelona, 1999 (22 edición revisada y ampliada, 2007); Arquitetura ex
critica, Barcelona, Ed. Gustavo Gili S.A., 2007. que no renuncia a la modernidad en los cuerpos modernos pero respetando la idiosincrasia de cada elemento en particular.

Renuncia, pues, a la construcción integrada y compacta, proponiendo una edificación dispersa de las diferentes partes, empezando por la más importante y significativa, que no es otra que la de despegarse de la construcción mas genuina (la lglesia) proponiendo una nueva relación de diálogo con el entorno más inmediato en base a una multipropuesta híbrida con soluciones diversas adaptadas a las necesidades y tipos de restauración o de nueva construcción para cada caso. Lo dicho, una propuesta híbrida en las formas, en las estrategias de cada caso, en los sistemas constructivos que califican cada época.

Arcadi Pla i Masmiquel es arquitecto y profesor de Proyectos en la E.T.S.A.Barcelona y en La Salle-Universitat Ramon Llull.
MONTANER, Josep Maria, Arquitectura y crítica en Latinoamérica, Bue-
nOS Aires, Ed. Nobuko, 2011. PALLASMAA, Juhani, Los ojos de la piel, Barcelona, Ed. Gustavo Gili,
S.A., 2006. PAWLEY, Martin, The strange death of architectural criticism. Collected
writings, London, black dog publishing, 2007 ROWE, Colin, KOETTER, Fred, Ciudad Collage, Barcelona, Ed. Gustavo
Gili S.A., 1981, 1998 . SAUNDERS, William S. (Ed.) The New Architectural pragmatism, Univer-
sity of Minnesota Press, Minneapolis/London, 2007. SOLÀ-MORALES, Ignasi de, Diferencias. Topografía de la arquitectura
contemporánea. Barcelona, Ed. Gustavo Gili S.A., 1995 .

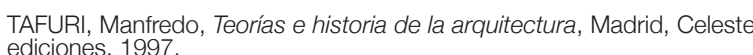
VÉSELY, Dalivor. Architecture in the Age of Divided Representation: The
Question of Creativity in the Shadow Of Production, Cambridge, Mass.
The MIT Press, 2004. ZUMTHOR, Peter, Atmósferas, Barcelona, Ed. Gustavo Gili S.A., 2006. 